\title{
How to Treat Off-campus Training Institutions
}

\author{
Liu Xiulian \\ School of Foreign Languages \\ Jianghan University \\ Wuhan, China
}

\author{
Li Yao \\ School of Electromechanical \& Architectural Engineering \\ Jianghan University \\ Wuhan, China
}

\begin{abstract}
The effects of off-campus training in institutions are discussed in this paper. It has been found that the off-campus training aims at making children more competent and meeting expectations of parents. Off-campus training education can promote the personalized development of students, and enrich the supply of educational services, so it is better to treat it rationally. As for the disordered off-campus training system, the authorities concerned should strengthen the management and normalize the corresponding rules, and make the off-campus training comply with regulations.
\end{abstract}

Keywords-off-campus training institutions; burden; management; treat

\section{INTRODUCTION}

On March 16, 2018, Minister of Education, Chen Baosheng, answered questions about "The efforts to create a fair and high-quality education for every child" at a press conference. When talking to reducing the burden of children, he said, "We all have to improve our educational quality instead of blindly pursuing so-called successful studies. Those training institutions show off incredible grades and advertising words, most of which are chicken soup and frauds. Influenced by such chicken soup, parents will easily fall into traps.” [1] The problem of excessive academic burden has become a hotspot in our society, mainly caused by excessive homework and off-campus training after school. In fact, excessive academic burden of primary and secondary school students is not a single issue [2], which involves family, school, government and society. In the following aspects, the relationship between off-campus training and learning in schools is analyzed.

\section{THE EXISTENCE CONDITIONS AND FUNCTIONS OF OFF- CAMPUS TRAINING}

The reason why a training institution can develop is that there must be a favorable situation and it can play an effective role.

\section{A. The product of Competition:}

Nowadays, a child in China is facing increasingly fierce competition in studying and working when he/she is very young, for there are few choices for civilians to get a rise in status. The fairest and most effective way is to take National College Entrance Examination. Through the examination, many civilians may have chance to get out of the bottom of society. Students who participate in National College Entrance
Examination must first have good academic performance in both primary school and middle school. It is impossible for students to be admitted by universities without arduous study, and even if students get their offers, they may hardly get into their ideal universities and majors to study. There are also both outstanding universities and general universities. For example, there are "University of 211 Projects" and "University of 985 Projects" in China, "Ivy League University" in the United States, "Russell University Group Alliance” and "Red Brick University" in the United Kingdom. Entering these top universities will inevitably require students to achieve good results in the pre-phase learning [3], for the score determines a student's fate.

In primary and secondary schools, it is almost impossible for a teacher to guarantee everyone in class with dozens of students to have a good command of what they are taught. So teachers can only teach in a way to make most students understand what they are taught. Responsible teachers may also teach excellent students more knowledge and help students with poor academic performance consolidate their foundation after class. However, with the accelerated pace of market economy and social life, this type of private tutoring for free has almost disappeared. In a bid to fill this gap in modern society, it is inevitable for parents and students to find corresponding solutions outside school, which leads to the emergence of off-campus training institutions. Off-campus training possesses various kinds of styles including one-to-one teaching, subject-separated teaching and basic teaching, which are complementary to school education [4]. Therefore, so long as the imbalance of high-quality educational resources exists, off-campus training education will survive [3]. For teachers, it is their responsibility to cultivate their students well. It is the pride of the teacher and the glory of the school especially when students get high grades. If students do not study well or the enrolment rates are inferior to those of other classes or other schools, some parents may complain that their children are not well taught and the teachers are incompetent. It has always been said that there are only incompetent teachers but no bad students, which inevitably increases pressure on teachers. To be a teacher is also difficult.

The teaching level and teaching effectiveness of a teacher are measured by the academic performance or enrolment rates of their students, so teachers naturally pay special attention to the scores of students. Students' burden is correspondingly augmented as a result of emphasizing grades. 
In addition, schools cultivate students in a standardized way, while society needs students with different personalities. Training institutions are not just teaching conventional courses but also providing other interesting activities, such as football, basketball, table tennis, tennis, swimming, singing, piano, calligraphy, skiing, roller skating, gymnastics, martial arts, dance, and painting. These projects are currently rare in schools, which are far from meeting the needs of students. Students can only be developed in training institutions. A considerable number of parents would like to see that their children are enthusiastic about a wide range of interests or become talents with skills. On the basis of respecting children's individual differences, initiative and personality, their children will be developed into distinctive social members, which also provides an existing environment for off-campus training.

\section{B. The Expectations of Parents}

All parents do not want their children to lose at the educational starting line and expect their children to become successful so that parents pay special attention to children's education. They try their best to find famous teachers for their children and make best use of extracurricular time to let children learn more knowledge and skills.

It is the duty of parents to care for the future of children, for they do not want children to grow up without good prospects and skills to make a living, and they worry their children cannot be useful for the society. Besides, some parents impose their unaccomplished achievements and ambitions on their children. Thus, it is a good excuse for parents to increase additional studying time and cultivate other skills and interests of their children. Some parents find that their children cannot keep up with their peers in school or have poor effects in study, but their own limited knowledge is not good enough to teach their children, so only through offcampus training or tutoring can their children catch up with the progress of study or improve the effect of learning. Though their children behave well, some parents still want to make them better than their peers through off-campus training. Taking advantage of the early age to learn everything quickly, others aim at improving skills and interests of their children, such as learning Kungfu, arts, sports, calligraphy, and painting. The competition this generation faces is much more intensified than that of any other generation in our history, so parents are compelled to increase learning burden on students. For a single person, when you are young, you are happy without studying hard, while you will never feel happy when you grow up. Therefore, lightening the burden is more easily said than done every year, and will never be achieved. Neither school nor parents and society can solve the problem of reducing burden. For every family, progress of children is the most promising and urgent thing. Many primary and secondary school students will take part in off-campus training in requirements of parents to learn more knowledge and master more expertise and skills so that they can be more competitive in future studies and employment. Hence, various of off-campus training institutions emerge as mushrooms because of the promising prospect, forming the current situation.
Some experts believe that parents should not only care about academic quality, but also focus on the lifelong development of their children. There are many ways to develop them to be a useful person. The experts consider that academic quality is only one of the factors, which is a key but not unique standard to evaluate if they can become successful or useful persons. It is known that one's diploma is not necessarily accord with his ability. However, most parents disagree with the opinion that diploma cannot represent ability.

A diploma represents for professional training of a person in one aspect. In fact, people with higher degrees contribute more to the society. Of course, employers do not consider diplomas as the most important standard to hire employees regardless of their abilities.

\section{The Influence of Chinese Traditional Culture}

Confucian culture has occupied a very important position in Chinese history for thousands of years. Under the influence of Confucian culture of "Learning is above doing any other things”, everyone is chasing after putting his name on the published list of successful candidate. Chinese have always believe that if you want to succeed, you must start working hard from childhood. Almost everyone knows that the famous Chinese saying goes, “A young idler, an old beggar”. So what is the effort? It means hard work and fighting for your future. It shows that if a person wants to become a successful person, he must start learning when he is very young. Liang Qichao once said, "Youngsters are strong so that China remains strong; youngsters are intellectual so that China will be intellectual, which shows that the future and hope of a country depends on the growth of adolescents. Without hard studying, how can a child be strong and intellectual? As we all know, with the present economic globalization, the competition among countries will finally focus on the aspects of comprehensive national strength and talents. Throughout history, most of the talented people have started their efforts since childhood. What these people get through is far from happy learning and easily studying. Without promoting his study skills in his youth, he will not be competent at all when growing up. Good study habits can be easily cultivated at an early age, but with aging, adults get a poor memory, have a great many of things to do and find it hard to resist temptations. Therefore, studying in youth is far superior to studying in adults. For most students with less talent and ability, it is necessary to extend their learning time, strengthen their efforts and improve their examination skills. Off-campus training meets all these requirements. At the same time, the governance of off-campus training institutions needs to change the adverse effects of cultural concepts and educational traditions, which will be a long and arduous process.

\section{The Influence of Society}

For one thing, we live in a drastically competitive society. The way that a society chooses talents is through examinations. No matter what we want to do, examinations are the effective way to certify your ability, which is a decisive factor in the distortion of the whole education system. Exam-oriented education makes children form a sense of social crisis when they are too young [5]. These examinations remind them that 
they will be weeded out if they fail to pass them so that parents exceedingly emphasis on their academic achievements, and the school would like to do everything possible to improve their scores.

For another thing, a child will be regarded as a tearaway if he does not study, will not be allowed to play with other children and, as a result, will be isolated either in the school or in the society. The future of a nation will become dim if children do not study hard at all. At the same time, apart from tutoring students, off-campus training courses also play an essential role in preventing students from danger, as it did in the case of the American program: 21st Century After-School tutoring program for Teens. The implementation of this program has effectively reduced the juvenile delinquency rate. "If you pay attention to juvenile delinquency, you will find out that it is common sense to reduce the rate of juvenile delinquency with the implementation of 21st Century AfterSchool tutoring program for Teens," says Barry Beck of the Oakland Children's Crime Research Organization in California [6].

\section{E. One of the Quality-oriented Education Results}

The aspects of quality-oriented education are quite large, including children's hobbies, skills and abilities. It is systematic, regular and consistent with students' study in school. This kind of pattern belongs to popularized education and refers to the learning abilities and effects of most children. There is also a deficiency, which does not consider the characteristics and personality requirements of children. The time for different students to spend on homework is different. Children with more spare time can learn other subjects to cultivate more interests for the individualized development, such as piano, swimming, martial arts, ball, calligraphy and painting, scientific activities and other kinds of interests and hobbies. We often speak of off-campus training with prejudice, actually, off-campus training can supplement the shortage of school education. Many of our sports talents, calligraphy and painting talents, and all kinds of talents are cultivated in training institutions. Therefore, off-campus training education meets the individualized learning needs of students, enriches the supply of education services and helps to improve the quality of students in all aspects, so off-campus training needs to be rationally treated. Currently, many primary and secondary schools do not attach enough importance to music, sports, calligraphy and other aspects of education, but only care for enrollment rates, while these aspects are well supplemented by off-campus training. Therefore, off-campus training should be a part of quality-oriented education

\section{MANAGEMENT AND NORMALIZATION OF OFF-CAMPUS TRAINING}

Since there is a need for off-campus training and there is no need to prohibit it, we should strengthen its management, normalize it, and protect the rights and interests of consumers, which will enable all kinds of training institutions to develop in a healthy and orderly way. This year, the report of the work of the government put forward "Focus on solving the burden of primary and secondary school students”, and the four Departments including the Ministry of education have issued the "Notice on effectively reducing the burden of primary and secondary school students after school and carrying out the special managements of the off-campus training institutions”. It is required that the classes, contents, enrolment objects and class time of training institutions should be put on records in the local educational administrative department and published to the society. It reflects that the administration of the government has gradually shifted from the approval to daily supervision on training institutions. Managements of offcampus training institutions will become the key target of the next stage of "burden reduction" [7]. At present, although government issued more detailed criteria for the training institutions, it is not enough. The key point is to strengthen management, promote normalization and have more practice. And these criteria require comprehensive assessment on training ideas, syllabuses, teaching methods, teachers, organization, and risk management of training institutions.

\section{CONCLUSION}

The above problems and reasons for the overburden of students are discussed. It shows that off-campus training, influenced by Chinese traditional culture, is the product of social competition, parents' expectation to cultivate their children's personality and ability, as well as the needs to improve academic achievement. The emergence of training institutions shows that it has its social foundation and corresponding circumstance. In fact, the training institutions have made some contributions to the society, so we do not make groundless accusations. What we need to do is to reinforce normalization and management for off-campus training institutions .

\section{REFERENCES}

[1] Chai Zang, Liu Bozhi. Efforts to Make Every Child Enjoy Fair and Good Quality Education. China Education Newspaper, 17 Mar. 2018. (In Chinese).

[2] Wang Yunsheng, Shen Siyuan. Effectiveness and Countermeasures of Primary and Secondary School Students' Burden Reduction in ShanghaiBased on the Survey of Supply and Demand Situation of Training Institutions. China Market, 4(2018) :107-110. (In Chinese).

[3] Li Na. The Development Trend of Shadow Education in China [J]. Journal of the Chinese Society of Education, 5 (2015): 54-57. (In Chinese).

[4] Xu Guangqin, Chen Shirong. A Discussion on the Present Situation of Primary School Students' Extracurricular Tutoring and Count [J]. Journal of Wenshan University, 29. 2 (2016) : 117-120. (In Chinese).

[5] Yuan Qian, Xiao Weiyan. An Investigation of the Reasons for Primary and Secondary School Students' Participation in Off-Campus Education and Training. Theory and Practice of Contemporary Education, 8. 6 (2016) :20-22. (In Chinese).

[6] Li Huiqing. The United States Intends to Expand the "High School After School Safety and Education for Teens". International and Comparative Education, 4 (2005): 94.

[7] Jin Jing. Off-Campus Training Industry Standards Need to Be Designed at the Top Level. China Education Newspaper, 15 Mar. 2018. (008): sec.8. (In Chinese). 